\title{
Comparative Analysis of PhD programs in Engineering Education
}

\section{Mr. Homero Gregorio Murzi, Virginia Tech}

PhD. student of Engineering Education at Virginia Tech.

\section{Mr. Prateek Shekhar, University of Texas, Austin}

Prateek Shekhar is a PhD student in the Department of Mechanical Education at the University of Texas at Austin. His research is focused in understanding students' and faculty's reaction to adoption of active learning based teaching methods in engineering classrooms. He holds a M.S. in Electrical Engineering from University of Southern California and B.S. in Electronics and Communication Engineering from India.

\section{Dr. Lisa D. McNair, Virginia Tech}

Lisa D. McNair is an Associate Professor of Engineering Education at Virginia Tech, where she also serves as co-Director of the VT Engineering Communication Center (VTECC). Her research interests include interdisciplinary collaboration, design education, communication studies, identity theory and reflective practice. Projects supported by the National Science Foundation include exploring disciplines as cultures, interdisciplinary pedagogy for pervasive computing design; writing across the curriculum in Statics courses; as well as a CAREER award to explore the use of e-portfolios to promote professional identity and reflective practice. 


\section{Comparative Analysis of PhD programs in Engineering Education}

\section{Introduction and Background}

The field of Engineering Education (ENGE) is a relatively new discipline that has been growing in the last years [1]. The purpose of the field is to increase the attraction and retention of students in engineering programs, as well as developing in engineering students, the required professional skills and competencies that are expected in industry to increase innovation in the globalized economy $[2,3]$. According to Jesiek, Newswander [4] "Engineering education research has experienced a notable scale up in recent years through the development of departments and degree programs, high-profile publication outlets, research agendas, and meetings" (p.39).

The discipline has emerged as an internationally recognized area of research and continues to expand every year through venues for continued discussion like the American Society of Engineering Education (ASEE), Frontiers in Education (FIE), Research in Engineering Education Symposium, national conferences; and peer reviewed publication outlets like the Journal of Engineering Education (JEE), the European Journal of Engineering Education (EJEE), and the International Journal of Engineering Education (IJEE). In the US, several universities like Arizona State University, University of Colorado Boulder, Colorado School of Mines, Embry-Riddle Aeronautical University, University of Illinois at Urbana-Champaign, University of Michigan, Northwestern University, Ohio State University, Penn State University, have established centers to support engineering faculty members in improving their pedagogical practices and perform research in other relevant areas of ENGE. In addition, engineering departments across several universities have started to recognize ENGE research in their doctoral programs. Furthermore, several specialized ENGE PhD programs are currently being offered in the country, reiterating the acceptance of ENGE as a rigorous field of inquiry.

The evaluation of graduate programs differ from undergraduate ones in terms of timeline and structuring of learning objectives [5]. Furthermore, interdisciplinary characteristics add another level of complexity to the evaluation process. The learning outcomes, degree requirements and structure of ENGE PhD programs are a unique combination of traditional engineering and 
education $\mathrm{PhD}$ program structures. This combining of two non-overlapping fields further necessitates the need for a focused approach towards the evaluation of the program. However, there is minimal information about the effectiveness of these dedicated $\mathrm{PhD}$ programs.

Considering the need to evaluate the quality of the $\mathrm{PhD}$ programs in ENGE, we think it is necessary to start by comparing the available programs in the country and the focus they have. This paper is a work in progress; we attempt to identify the relevant engineering education $\mathrm{PhD}$ programs in the country and compare them to understand if there is a consensus on how the field is perceived. This initial work will build up into a bigger plan of constructing a full evaluation of $\mathrm{PhD}$ 's programs in ENGE and to measure the impact that the field has had in the engineering discipline. More specifically, in this paper we will answer the following research questions:

1. Do all the $\mathrm{PhD}$ programs in engineering education have the same purpose?

2. Are there similitudes between the programs learning outcomes?

3. Are there similitudes between the milestones required to promote the learning outcomes?

4. Is there differentiation in the focus of the $\mathrm{PhD}$ programs?

The ENGE field keeps growing with new programs being developed around the country. In addition, centers for Engineering Education are being created to support faculty development in engineering. However, there is no information about the effectiveness of ENGE in the transformation of the engineering field. There is no information on how well departments are satisfying the needs of the external environment, neither how effective are the curricular designs to help students develop their career goals. The purpose of this paper is to compare the $\mathrm{PhD}$ programs in engineering education in the country to be able to understand how similar (or not) they are regarding their purpose and final goal. The information presented can start a conversation on how to measure the effectiveness of $\mathrm{PhD}$ programs in ENGE and its impact in the engineering field.

\section{Program Evaluation}


The term evaluation is defined as "the identification, clarification, and application of defensible criteria to determine an evaluation object's value (worth or merit) in relation to those criteria" [6]. The process of evaluation requires identification of evaluation criteria and standards, collection of relevant data and application of the defined evaluation criteria to measure the value, performance or effectiveness [6]. Particularly for evaluation of an academic program, the process follows an accreditation-like format where its effectiveness in achieving program educational objectives (PEO's) and program outcomes (PO's) is tested. Program educational objectives are broad goals addressing mission statements and interests of its stakeholders. On the other hand, program outcomes are the educational objectives that measure the level of knowledge and skills attained by graduates as a result of the program [7].

Benson, Becker [8] analyzed the engineering education field. They focused their research in understanding departments, degrees and directions in the field. First they started by providing with history about the creation of the different departments and schools of engineering education in the country, and then they differentiated certificates, courses, and degree programs. They also outlined career opportunities for ENGE graduates. The authors concluded that the engineering education field is growing and gaining more acceptance every day. However, to see long-term results of the systematic change engineering education brings, it is necessary to: (i) increase the number of departments and centers, (ii) hire and train more faculty members aware of the need of breaching the gap of research and practice, and (iii) promote discipline-based research in engineering schools.

Benson, Becker [8] argued that the ENGE graduates should be able to: (i) Conduct and direct cutting-edge education research, including the areas of epistemologies, learning mechanisms and systems, pedagogical implementation, diversity and inclusiveness, and assessment; (ii) Apply the results of such research to the courses, curricula, and educational policies in academic and nonacademic settings; (iii) Be prepared for academic, government, and industry positions related to the lifelong education of engineers and scientists; (iv) Actively participate and act as leaders in their fields through professional organizations, conferences, government organizations, workshops, and related activities to advance engineering and science education, and to develop highly qualified engineers, scientists, and discipline-based education researchers. In this paper 
we will verify if the PhD in ENGE learning outcomes match the outcomes suggested by Benson, Becker [8] and evaluate if all the programs have a similar purpose.

\section{Methods}

In order to answer the research questions we took a qualitative approach. Information from the different $\mathrm{PhD}$ programs in Engineering Education was collected through their websites and analyzed by the researchers. Initially we did an online search to identify the relevant programs existing in the country. We developed the following criteria to consider the program to be analyzed:

1. The program offers a $\mathrm{PhD}$ or Doctorate degree in Engineering Education, or another title that brings together STEM disciplines and education.

2. The program has alumni.

3. The program has been operating for at least five years.

4. The program is offered by an engineering school or college.

After the initial search, four programs meet the criteria. We analyzed those four programs in detail and gathered all the available information about them. In the next section we will provide a general description of the programs and then the comparative analysis about the main aspects of the programs will be presented in the table 1 .

\section{Description of PhD programs in Engineering Education}

\section{Purdue University}

The School of Engineering Education at Purdue was established in 2004. It was the first academic department in the world. They were also the first to offer a doctoral program in engineering education. The school was created by incorporating the First-Year Engineering program and multidisciplinary engineering/interdisciplinary engineering studies in one department. The focus of the school is to promote rigorous research regarding best pedagogical practices, student learning, and professional practices in the field of engineering [9]. 
One of the distinctive characteristics of the program has been the focus on closing the gap between educational research and engineering practice. The program prepares students to develop effective teaching practices informed by research that translates in developing the correct curricula, creating assessment tools that measure the positive impact, and creating learning environments that develop tomorrow's engineers [9].

\section{Virginia Tech}

The $\mathrm{PhD}$ program in Engineering Education at Virginia Tech is one of the few $\mathrm{PhD}$ programs in the field around the country. The program focuses on incorporating theory with real life application to form engineering educators prepared to be teachers and scholars in this evolving field [10]. The Engineering Education department at Virginia Tech was established in 2004 and the $\mathrm{PhD}$ program in 2008.

The department's mission is to "advance the engineering profession by integrating research and teaching to impact learning and practice"[10], its vision is to "prepare students to be exceptional engineers and educators while serving as an international beacon for engineering and research" [10].

The $\mathrm{PhD}$ program is designed to transform graduate students into leaders and change agents in the engineering field of ENGE. Through research in engineering education, graduates are able to transform engineering classrooms, design effective research, and evaluate engineering programs. The ultimate goal is to improve engineering schools.

The cross-disciplinary $\mathrm{PhD}$ program is designed specifically to prepare graduates for careers across the entire range of engineering education. The inherent flexibility of the program allows students to tailor their curriculum and their research to prepare them to achieve their goals in engineering education [10]. The $\mathrm{PhD}$ program is designed to emphasize rigorous research and incorporate it into teaching practices and learning processes in engineering contexts.

\section{Clemson}


The program in science, technology, engineering, and mathematics (STEM) education research was created at the Department of Engineering \& Science Education, in the College of Engineering and Science at Clemson University. The program includes both engineering education and science education in a college of science/engineering. The program offers the doctoral degree in Engineering and Science Education where students are able to develop rigorous research in the growing field of engineering and science education. Faculty members in the program are experts in science education as well as engineering education. They offer different research options under their research programs [11].

Students in the program undergo extensive research in STEM education and are exposed to a variety of topics in that regard. They are encouraged to develop new theories in STEM education and to implement research results in practice in the classroom [11]. The program is based on Discipline Based Education Research (DBER), which combines knowledge of teaching and learning with deep knowledge of discipline specific science or engineering content [11].

\section{Utah State University}

The PhD program at Utah State University was developed to meet the challenge of training the leaders that will educate engineers that can adapt to the needs of the globalized world. The program was created to produce graduates with proficiency in engineering pedagogy and expertise in engineering education research, that are responsible for designing engineering course pedagogy, curriculum, and leveraged research to improve learning outcomes [12].

The purpose of the faculty members in the program is to use ENGE research into their teaching practices to develop doctoral students as effective engineering educators and researchers. They are encouraged to promote innovative cutting-edge research [12].

The Doctorate of Philosophy in Engineering Education at Utah State University is offered through the Engineering and Technology Education Department. According to Benson, Becker [8] its emphasis is on "the learning and teaching of engineering design, producing students with 
proficiency in developing engineering design skills in others, and expertise in research into how those skills are best learned and taught." (p. 1044)

\section{Discussion}

Table 1 in the appendix presents the comparative analysis of the $\mathrm{PhD}$ programs in Engineering Education in the country. The analysis focused on six characteristics that were compared and analyzed based on the information available on their websites. The six items analyzed were (i) name of the degree granted in the program; (ii) goal of the program; (iii) expected learning outcomes of the program; (iv) requirements to complete the program and obtain the degree; (v) focus of the core courses in the program; and (vi) milestones that students need to approve in order to obtain the degree.

The emphasis on conducting rigorous research to improve engineering programs is the predominant underlying theme for all four ENGE PhD programs. However, the program goals differ on the lines of expanding research to other STEM disciplines. While Virginia Tech and Purdue focus solely on engineering education, Utah State and Clemson University expand their research goals to a larger STEM community that includes (but not limited to) mathematics, science, and technology.

The learning outcomes of all four ENG PhD programs have a common ground that places emphasis on the ability to conduct effective educational research in the areas of engineering curriculum, pedagogy, assessment, and faculty development. However, two minor differences exist in the learning outcomes of Utah State University and Clemson University. For Utah State University, the difference arises from the additional focus on pre-college engineering education in the learning outcomes. This is in alignment with its program goal to serve a larger STEM community. On the other hand, Clemson University includes the ability of its graduates to get hired as a traditional faculty in engineering, science, and education departments as an additional learning outcome. This focus on job prospects highlights the unpredictability students with interdisciplinary research background might face when they graduate out of their $\mathrm{PhD}$ programs. 
The program requirements align with the disciplinary idea of combining engineering and education disciplines. In general, the coursework comprises of core engineering courses allowing the students to develop a graduate level of understanding of engineering content, as well as, understanding different educational theories. To build a background about engineering education as a field of inquiry, these programs require students to take foundational engineering education courses which cover the history and philosophy of engineering education, relevant theoretical frameworks, assessment and evaluation techniques, current research and future trends, etc. Lastly, to develop the ability to conduct educational research, the programs require the student to undergo courses involving educational, psychological and social theories, qualitative and quantitative research methods.

Regarding milestones, the programs are very consistent with requiring students to demonstrate that they can conduct independent research after they finish their degree. All of them require for students to take an exam to demonstrate they can understand and apply scientific literature to expand engineering education research. In addition, all the students are required to have teaching experience in order to complete the program. Also, students are required to complete and defend a doctoral dissertation. Utah State University is the only program that requires students to have at least one publication on a peer-reviewed journal in order to complete the degree.

Based on the website information analysis it is possible to infer that the $\mathrm{PhD}$ programs in engineering education have a similar purpose (i.e. to bring educational research to practice in engineering classrooms). However, with the limited information available is not possible to determine if students after graduation feel prepared to work at research institutions, teachingcentered institutions, industry, or government. In addition, it is not possible to explain how students perceive the purpose of the milestones they have during the program, how those milestones are relevant to their future job, and what are the intentions behind the faculty members when are evaluating the different milestones. Therefore, it is necessary for future studies to actually collect qualitative data through interviews with faculty members, students, alumni, and employers in order to understand better these questions.

\section{Limitations}


One of the limitations of this paper is that the information was obtained from the websites of the four universities. There was no confirmation about the validity of the information, neither if it was up to date. In order to expand the comparison in future research, key stakeholders for the engineering education field will be interviewed in order to obtain more relevant information. In addition, because of our search criteria we didn't include engineering education programs offered by schools of education. In the future we plan not only to include all the programs but also to include engineering education centers as well.

\section{Conclusion}

The comparative analysis presented in this paper allowed us to confirm that there are several similitudes in the $\mathrm{PhD}$ programs in engineering education around the country. Especially, in the extensive focus on research, the need of teaching experience, the focus on research methods in engineering education, and also the requirement of relate the coursework to a specific discipline in engineering or STEM.

However, there are also some discrepancies regarding the purpose, the focus of the goals, and the learning outcomes of the PhD programs. The program in Utah State University focuses on understand the main problems in the field of engineering education, while programs like Virginia Tech and Purdue focus on improve engineering classrooms thorough effective pedagogical strategies informed by engineering education research. The program in Clemson focuses on closing the gap between research and practice in engineering and science education.

After the review is also notable that the PhD programs at Purdue University and Virginia Tech are the most similar ones. The structure, purpose, and focus of the programs are very similar and seems like both Universities are on the same page regarding what is expected on the field of engineering education.

\section{Future implications}


The results presented in this work in progress confirm that the growing engineering education field has several $\mathrm{PhD}$ programs offering similar things. However, it is necessary to explore further and do an extensive evaluation of the field. As part of our research agenda we will develop an evaluation proposal of the $\mathrm{PhD}$ programs in the field that will measure the impact that the programs are having in the engineering field. The research will be conducted in all the different universities in the country offering the program. Surveys and interviews will be conducted with Faculty members, administrators, alumni, faculty in charge of hire engineering educators, and current graduate students to understand their perspectives about engineering education and its impact in the engineering field. The evaluation proposal will not only serve as an indicator of the stage of the $\mathrm{PhD}$ program in Engineering Education, but also will serve as a model to evaluate the effectiveness and impact of $\mathrm{PhD}$ programs despite the field.

\section{References}

1. Borrego, M., Development of engineering education as a rigorous discipline: A study of the publication patterns of four coalitions. Journal of Engineering Education, 2007. 96(1): p. 5-18.

2. Brophy, S., et al., Advancing engineering education in P - 12 classrooms. Journal of Engineering Education, 2008. 97(3): p. 369-387.

3. Lucena, J., et al., Competencies Beyond Countries: The Re - Organization of Engineering Education in the United States, Europe, and Latin America. Journal of Engineering Education, 2008. 97(4): p. 433-447.

4. Jesiek, B.K., L.K. Newswander, and M. Borrego, Engineering education research: Discipline, community, or field? Journal of Engineering Education, 2009. 98(1): p. 39-52.

5. McNair, L.D. and M. Borrego. Graduate students designing graduate assessment: EPortfolio design as problem-based learning. in Frontiers in Education Conference (FIE), 2010 IEEE. 2010. IEEE.

6. $\quad$ Fitzpatirck, J.L., J.R. Sanders, and B.R. Worthen, Chapter 1, in Program Evaluation : Alternate Approaches and Practical Guidelines. 2012, Pearson: Boston.

7. Felder, R.M. and R. Brent, Designing and teaching courses to satisfy the ABET engineering criteria. Journal of Engineering Education, 2003. 92(1): p. 7-25.

8. Benson, L.C., et al., Engineering education: Departments, degrees and directions. International Journal of Engineering Education, 2010. 26(5): p. 1042.

9. School of Engineering Education, P.U. Engineering Education. n.d. [cited 2014 November 18th]; Available from: https://engineering.purdue.edu/ENE.

10. Department of Engineering Education, V.P.I.a.S.U. Engineering Education. n.d. [cited 2014 August 06th]; Available from: http://www.enge.vt.edu/.

11. Department of Engineering and Science Education, C.U. Engineering and Science Education. n.d. [cited 2014 November 16th]; Available from: http://www.clemson.edu/ese/.

12. Engineering Education, U.S.U. Engineering Education. n.d. [cited 2014 November 19th]; Available from: http://www.eed.usu.edu/. 




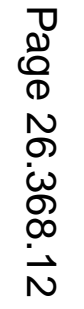

